\title{
FATORES EDÁFICOS E AS VARIAÇÕES FLORÍSTICAS DE UM TRECHO DE MATA CILIAR DO RIO GUALAXO DO NORTE, MARIANA, MG ${ }^{1}$
}

Iolanda de Sena Gonçalves², Herly Carlos Teixeira Dias³ ${ }^{3}$ Sebastião Venâncio Martins ${ }^{3}$ e Agostinho Lopes de Souza ${ }^{3}$

\begin{abstract}
RESUMO - Este trabalho teve como objetivo verificar a correlação entre a distribuição de espécies arbóreas

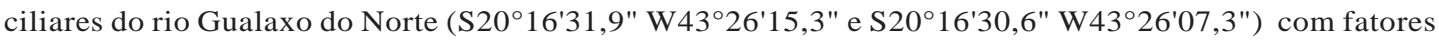
edáficos, assim como se existem espécies de ocorrência restrita à área de depleção ciliar que possam ser indicadas para recuperação de matas ciliares. As parcelas foram alocadas em 1 ha dividido em três blocos com declividades distintas. Todos os indivíduos com circunferência do tronco a 1,30 m do solo igual ou superior a $15 \mathrm{~cm}$ foram registrados e identificados. Foram coletadas cinco amostras simples de solo em cada parcela para análises químicas de fertilidade. A ordenação dos dados de solo e vegetação foi realizada pela análise de correspondência canônica (CCA), que indicou que variações na fertilidade, na acidez do solo e na altitude estavam influenciando a distribuição da vegetação arbórea ao longo do gradiente topográfico. Albizia hassleri, Bathysa meridionalis, Cariniana estrelensis, Casearia gossypiosperma, Casearia sp., Cecropia hololeuca, Himatanthus lancifolius, Luehea grandiflora, Picramnia sp., Platypodium elegans, Pseudopiptadenia contorta, Tibouchina candoleana e Virola oleifera são espécies adaptadas a condições edáficas com elevada acidez e fertilidade muito baixa, apresentando potencial para utilização em projetos de recuperação de áreas degradadas, principalmente de encostas e topo de morros. Já Casearia sylvestris, Dalbergia villosa, Dendropanax cuneatus, Machaerium aculeatum, Machaerium stiptatum, Ocotea odorifera, Ocotea pulchella, Rollinea longifolia, Schinus terebinthifolius, Tibouchina granulosa, Vernonia piptocarphoides e Vismia sp. estavam correlacionadas com solos menos ácidos, mais férteis e mais próximos ao rio, apresentando potencial para a restauração florestal em áreas ciliares.
\end{abstract}

Palavras-chave: Relação solo-vegetação, Mata Ciliar e Análise de correspondência canônica.

\section{INFLUENCE OF SOIL FACTORS ON THE FLORISTIC VARIATIONS OF A SECTION OF RIPARIAN FOREST IN THE RIVER GUALAXO DO NORTE, MARIANA, MG}

\begin{abstract}
The objective of this was to investigate the correlation between the distribution of tree species of the riparian forest of Gualaxo do Norte river (S20 $16^{\prime} 31.9^{\prime \prime}$ W43⒉ $6^{\prime} 15.3^{\prime \prime}$ and S20 $16^{\prime} 30.6^{\prime \prime}$ W43 $\left.3^{\circ} 6^{\prime} 07.3^{\prime \prime}\right)$ with soil factors and to find if there are species of occurrence restricted to depletion of riparian forests that can be indicated for recovery of riparian forest. The plots were allocated in 1-ha divided into three blocks with different steepness. All of the individuals with a trunk circumference at $1.30 \mathrm{~m}$ above ground equal to or greater than $15 \mathrm{~cm}$ were recorded and identified. Five simple samples of soil were collected in each plot for fertility chemical analysis. The ordination of the soil and vegetation data was made by the analysis of canonical correspondence (CCA) that indicated that variations in the chemical fertility, acidity of the soil and height were influencing the distribution of the tree vegetation over the topographical gradient.Albizia hassleri, Bathysa meridionalis, Cariniana estrelensis, Casearia gossypiosperma, Casearia sp., Cecropia hololeuca, Himatanthus lancifolius, Luehea grandiflora, Picramnia sp., Platypodium elegans, Pseudopiptadenia contorta, Tibouchina candoleana and Virola oleifera are species adapted to soil conditions with high acidity and very
\end{abstract}

\footnotetext{
${ }^{1}$ Recebido em 24.06.2009 e aceito para publicação em 31.10.2011.

${ }^{2}$ Faculdade de Ciências Biológicas e da Saúde, FACISA, Brasil. E-mail: <iolanda.gonçalves@ufv.br>.

${ }^{3}$ Departamento de Engenharia Florestal da Universidade Federal de Viçosa, UFV, Brasil. E-mail: <herly@ufv.br >, <venancio@ufv.br> e<alsouza@ufv.br>.
} 
low fertility, presenting potential for use in projects of recovery of degraded areas, mainly of hillsides and top of hills. Already Casearia sylvestris, Dalbergia villosa, Dendropanax cuneatus, Machaerium aculeatum, Machaerium stiptatum, Ocotea odorífera, Ocotea pulchella, Rollinea longifolia, Schinus terebinthifolius, Tibouchina granulosa, Vernonia piptocarphoides and Vismia sp. are correlated with soils less acid, more fertile and closer to the river, presenting potential for the forest restoration in riparian zones.

Keywords: Soil-vegetation relation, Riparian Forest and Canonical correspondence analyses..

\section{INTRODUÇÃO}

As matas ciliares constituem importante elemento caracterizador das paisagens do Centro-Sul do Brasil, margeando os cursos d’água dessa região e apresentando fisionomia que se destaca nitidamente dos campos ou cerrados vizinhos ou que se funde gradualmente a outros tipos florestais adjacentes (OLIVEIRA FILHO et al., 1994).

A velocidade de devastação das matas ciliares ameaça os ecossistemas florestais primários, restringindoos basicamente a áreas protegidas. Os poucos remanescentes florestais ainda existentes necessitam urgentemente de pesquisas básicas, no sentido de promover a conservação e preservação deles (MARANGON et al., 2003). Além disso, os estudos direcionados às florestas secundárias são necessários, uma vez que as formações vegetais em regeneração constituem importante laboratório natural (RIBAS et al., 2003).

Comparações florísticas entre remanescentes de matas ciliares mostram que essas formações florestais apresentam grande diversidade e baixos valores de similaridade, mesmo entre áreas de proximidade espacial (DURIGAN; LEITÃO FILHO, 1995). Nas áreas ribeirinhas são encontrados diversos tipos de solos, os quais variam essencialmente em função do maior ou menor grau de hidromorfismo que acontece nesse terreno (JACOMINE, 2000).

Estudos de vegetação correlacionados com as características pedológicas são de grande importância quando se desejam desenvolver trabalhos de natureza ecológica mais detalhados, pois o solo e as espécies apresentam relações essenciais, as quais são fundamentais para o estabelecimento da vegetação e, por consequência, para a escolha de espécies a serem utilizadas em projetos de recuperação de áreas degradadas (SILVA, 1989).

Revista Árvore, Viçosa-MG, v.35, n.6, p.1235-1243, 2011
Autores como Martins et al. (2003) e Jacomine (2000) recomendam a realização de estudos de correlação específica entre as diversas classes de solos e respectivas formações florestais, com destaque para a ocorrência de espécies indicadoras, visando à definição de estratégias para conservação e manejo de remanescentes florestais, bem como a restauração florestal de áreas já degradadas.

Este trabalho teve por objetivo verificar a correlação entre a distribuição de espécies arbóreas ciliares do rio Gualaxo do Norte com fatores edáficos, assim como se existiam espécies de ocorrência restrita à área de depleção ciliar que pudessem ser indicadas para recuperação de matas ciliares.

\section{MATERIAL E MÉTODOS}

\section{1. Área de estudo}

O fragmento florestal estudado está localizado no município de Mariana (Figura 1) (4326’15"$43^{\circ} 26^{\prime} 07^{\prime \prime} \mathrm{W}$ e $20^{\circ} 16^{\prime} 31^{\prime \prime}-20^{\circ} 16^{\prime} 30^{\prime \prime S}$ ), na região central de Minas Gerais (IBGE, 2008). Este município está inserido regionalmente na bacia hidrográfica do rio Doce, (MARIANA, 2008). A bacia do rio Gualaxo do Norte possui área de aproximadamente $253,16 \mathrm{~km}^{2}$, com padrão de drenagem em treliça e ocasionalmente dendrítico (SOUZA et al., 2005). No trecho estudado, com cotas altimétricas entre $706 \mathrm{~m}$ e $735 \mathrm{~m}$, o rio possui $12 \mathrm{~m}$ de largura no período de seca e aproximadamente $20 \mathrm{~m}$ no período chuvoso, tendo assim 50 m de Área de Preservação Permanente, de acordo com a Resolução CONAMA n 303/02 (BRASIL, 2002).

O clima da região, pela classificação climática de Köeppen, é o Cwa, clima temperado chuvoso (mesotérmico) com inverno seco e verão chuvoso, sendo a temperatura média do mês mais frio inferior a $18^{\circ} \mathrm{C}$ e a do mês mais quente superior a $22^{\circ} \mathrm{C}$ (OZÓRIO, 2000).

O relevo da bacia é classificado, segundo Souza et al. (2005), como predominantemente ondulado, com declives na faixa de 20 a $40 \%$. 


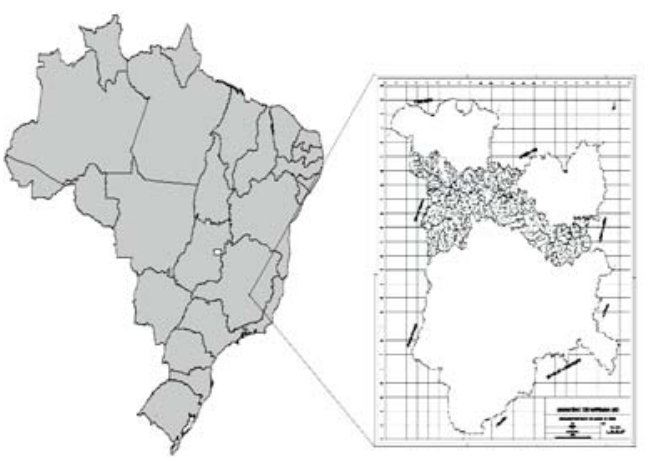

Figura 1 - Localização do município de Mariana e da bacia do rio Gualaxo do Norte em destaque, Minas Gerais.

Figure 1 - Location of the municipality of Mariana and of the Basin of Gualaxo do Norte river is highlighted, Minas Gerais.

\subsection{Amostragem}

Para o estudo fitossociológico, utilizou-se o método de parcelas (MUELLER-DOMBOIS; ELLENBERG, 1974), com a alocação de 19 parcelas na margem esquerda do rio Gualaxo do Norte. As parcelas foram distribuídas em três blocos: o primeiro com área de $3.500 \mathrm{~m}^{2}$, distribuídos em sete parcelas de 10 m x 50 m; o segundo com área de $3.000 \mathrm{~m}^{2}$, distribuídos em cinco parcelas de $10 \mathrm{~m}$ x $60 \mathrm{~m}$; e o terceiro com área de $3.500 \mathrm{~m}^{2}$, distribuídos em sete parcelas de $10 \mathrm{~m}$ x $50 \mathrm{~m}$, totalizando uma área de $10.000 \mathrm{~m}^{2}$. Nesses blocos, as parcelas foram marcadas perpendicularmente ao rio.

Foram amostrados indivíduos arbóreos vivos, com circunferência do tronco a 1,30 m acima do solo (CAP), igual ou maior a $15 \mathrm{~cm}$. A identificação do material botânico foi realizada mediante consultas à literatura especializada, comparações com o Herbário do Departamento de Biologia Vegetal da Universidade Federal de Viçosa (VIC) e consultas a especialistas em determinados grupos vegetais.

Para a organização sistemática dos táxons foi adotado o Sistema de Cronquist(1981), exceto para a família Leguminosae, para a qual foi adotada a proposição taxonômica da APG II - Angiosperm Phylogeny Group II (SOUZA; LORENZZI, 2005). Para a confirmação dos nomes, bem como seus autores, utilizou-se o índice de espécies do programa Index Kewensis 2.0 (ROYAL BOTANICAL GARDENS, 1993), o índice de espécies do Missouri Botanical Garden. (MOBOT, 2008) e literaturas especializada.

\subsection{Análise de solos}

Para as análises químicas de fertilidade do solo, foram coletadas cinco amostras simples em cada parcela, com o auxílio de trado holandês na profundidade de 0 a $20 \mathrm{~cm}$. As amostras coletadas foram quatro nos vértices e uma no centro da parcela. Após a realização das análises, foi calculada a média das cinco amostras para se obter um valor único por parcela.

As análises químicas de fertilidade foram realizadas no Departamento de Solos da Universidade Federal de Viçosa, tendo sido analisados o pH em água, o fósforo $(\mathrm{P})$ e o potássio $(\mathrm{K})$ disponíveis, o cálcio (Ca2+), o magnésio (Mg2+) alumínio (Al3+), o hidrogênio + alumínio $(\mathrm{H}+\mathrm{Al})$, a soma de bases $(\mathrm{SB})$, o índice de saturação por alumínio (m), a capacidade de troca catiônica efetiva [CTC (t)], a capacidade de troca catiônica a pH 7,0 [(CTC (T)), o índice de saturação por bases (V) e o fósforo remanescente (P-rem). Todas as análises seguiram os procedimentos descritos no Manual de Métodos de Análise de Solo (EMBRAPA, 1997).

\subsection{Ordenação de dados de solo e vegetação}

Para verificar se existiam correlações entre a distribuição das espécies ao longo do gradiente topográfico e os fatores edáficos, foram elaboradas duas matrizes: uma de vegetação e outra de variáveis ambientais. Foram incluídas nesta análise apenas as espécies registradas com 10 ou mais indivíduos no levantamento, uma vez que as espécies com densidade muito baixa aumentam o volume de cálculos e interferem pouco nos resultados (GAUCH, 1982). A matriz da vegetação foi composta pela abundância das espécies nas respectivas parcelas, enquanto a das variáveis ambientais foi composta pelos valores obtidos nas respectivas análises do $\mathrm{pH}$ em água, $\mathrm{P}, \mathrm{K}, \mathrm{Ca}^{2+}, \mathrm{Mg}^{2+}$, $\mathrm{Al}^{+3}, \mathrm{~V}, \mathrm{~m}$, distância do rio e da cota altimétrica da parcela na sua extremidade superior. Para analisar as correlações entre os gradientes ambientais e vegetacionais, foi utilizada a análise de correspondência canônica (CCA), empregando-se o programa PC-ORD (McCUNE; MEFFORD, 1997).

Utilizou-se o teste de Monte Carlo para avaliar o nível de significância dos eixos de ordenação canônica, o qual permite analisar a probabilidade de acerto nas relações encontradas entre as variáveis vegetais e as ambientais (TER BRAAK; PRENTICE, 1988). 


\section{RESULTADOS}

\subsection{Análise de solo}

Os resultados da análise química do solo são apresentados na Tabela 1, e suas interpretações foram estabelecidas de acordo com Tomé Júnior (1997).

\subsection{Análise de correspondência canônica}

Os autovalores (ë) dos dois primeiros eixos de ordenação canônica foram 0,439 para o eixo 1 e 0,235 para o eixo 2, com o primeiro eixo explicando $20,3 \%$ da variância total dos dados e o segundo, 10,9\% (total acumulado: 2,16). AACC produziu correlações espécieambiente nos dois primeiros eixos: 0,987 (eixo 1) e 0,976 (eixo 2), e o teste de Monte Carlo apresentou probabilidade $(\mathrm{P}=0,01)$ nos dois primeiros eixos.

Entre as nove variáveis ambientais incluídas na ACC, oito apresentaram correlação mais forte com o eixo 1 e apenas a variável K mostrou correlação mais forte com o eixo 2. O primeiro eixo correlacionou-se negativamente com grande parte das variáveis, exceto $\mathrm{pH}$, Ca, Mg e V. O eixo 1 apresentou correlações mais forte com $\mathrm{pH}$ (positiva) e com m (negativa). Observou-se que o $\mathrm{pH}$ e m apresentaram grande polarização no eixo 1 , e CTC(T) e m mantiveram valores muito próximos de zero no eixo 2, não estando fortemente correlacionados com esse eixo. A ordenação das parcelas está representada na Figura 2 e a das espécies na Figura 3. As espécies utilizadas para as análises e suas referidas siglas encontram-se na Tabela2.

\section{DISUSSÃO}

\subsection{Fertilidades do solo}

A maioria das amostras apresentou acidez elevada, uma vez que $84 \%$ das parcelas tiveram valores de $\mathrm{pH}$ em água menores que 5. Em condições naturais, o pH é utilizado como um dos indicativos de condições gerais de fertilidade do solo: valores altos indicam boa fertilidade e valores baixos, baixa fertilidade. As parcelas com maiores

Tabela 1 - Resultados das análises químicas de fertilidade das amostras superficiais $(0-20 \mathrm{~cm})$ de solo coletadas na margem esquerda do rio Gualaxo do Norte, Mariana, MG. Em que: SB = soma de bases trocáveis; $t$ = capacidade de troca catiônica efetiva; $\mathrm{T}$ = capacidade de troca catiônica a pH 7,0; V = índice de saturação por bases; $\mathrm{m}=$ índice de saturação por alumínio; e P-rem = fósforo remanescente. Os valores de cada variável em cada parcela representam a média de cinco amostras por parcela.

Table 1 - Results of the chemical analyses of fertility of the superficial samples $(0-20 \mathrm{~cm})$ of soil collected in the left bank of Gualaxo do Norte river, Mariana, MG. In which: SB = sum of exchangeable bases; $t=$ capacity of effective cation exchange; $T$ = capacity of cation exchange at $p H$ 7.0; $V=$ base saturation ratio; $m$ = aluminium saturation index; and P-rem = remaining match. The values of each variable in each plot represent the average of five samples per plot.

\begin{tabular}{|c|c|c|c|c|c|c|c|c|c|c|c|c|c|c|}
\hline \multirow[t]{2}{*}{ Parcela } & \multirow{2}{*}{$\begin{array}{c}\mathrm{pH} \\
\mathrm{H}_{2} \mathrm{O}\end{array}$} & $\mathrm{P}$ & $\mathrm{K}$ & $\mathrm{Ca}$ & $\mathrm{Mg}$ & $\mathrm{Al}$ & $\mathrm{H}+\mathrm{Al}$ & SB & $\mathrm{t}$ & $\mathrm{T}$ & $\mathrm{V}$ & $\mathrm{m}$ & \multirow{2}{*}{$\begin{array}{c}\text { P_rem } \\
\text { mg/L }\end{array}$} & \multirow{2}{*}{$\begin{array}{l}\text { Distância } \\
\text { do rio m }\end{array}$} \\
\hline & & \multicolumn{2}{|c|}{$-\mathrm{mg} / \mathrm{dm}^{3}-$} & & & 0 & $\mathrm{ol}_{\mathrm{c}} / \mathrm{dm}^{3}$ & & & & \multicolumn{2}{|c|}{ - $\%$} & & \\
\hline P1 & 5,20 & 1,10 & 44,20 & 0,40 & 0,41 & 0,15 & 6,22 & 0,93 & 1,08 & 7,15 & 13,62 & 18,02 & 29,96 & 10 \\
\hline $\mathbf{P} 2$ & 4,68 & 1,30 & 56,00 & 0,46 & 0,63 & 1,24 & 9,58 & 1,23 & 2,47 & 10,81 & 11,54 & 50,62 & 17,70 & 20 \\
\hline P3 & 4,49 & 2,20 & 70,20 & 0,58 & 0,66 & 1,99 & 11,74 & 1,42 & 3,42 & 13,16 & 10,78 & 52,46 & 17,48 & 30 \\
\hline P4 & 4,10 & 2,06 & 73,00 & 0,53 & 0,65 & 3,36 & 14,10 & 1,19 & 4,79 & 15,48 & 9,86 & 67,32 & 14,64 & 40 \\
\hline P5 & 4,31 & 2,26 & 65,40 & 0,42 & 0,45 & 2,38 & 11,10 & 1,04 & 3,42 & 12,14 & 8,96 & 68,46 & 15,00 & 50 \\
\hline P6 & 4,08 & 1,22 & 57,20 & 0,13 & 0,25 & 2,73 & 12,44 & 0,52 & 3,24 & 12,96 & 4,02 & 83,70 & 14,42 & 60 \\
\hline P 7 & 4,02 & 1,58 & 48,40 & 0,10 & 0,18 & 3,22 & 13,38 & 0,40 & 3,62 & 13,78 & 2,98 & 88,90 & 12,24 & 70 \\
\hline P8 & 5,78 & 1,08 & 45,00 & 0,80 & 0,60 & 0,00 & 4,60 & 1,52 & 1,52 & 6,12 & 25,10 & 0,00 & 27,98 & 10 \\
\hline P9 & 5,04 & 1,32 & 33,17 & 0,16 & 0,33 & 0,08 & 6,07 & 0,57 & 0,65 & 6,63 & 8,63 & 11,13 & 17,43 & 20 \\
\hline P10 & 4,57 & 1,47 & 47,67 & 0,06 & 0,27 & 1,05 & 8,88 & 0,45 & 1,50 & 9,34 & 5,32 & 52,48 & 13,25 & 50 \\
\hline P11 & 4,13 & 1,75 & 41,00 & 0,13 & 0,18 & 2,91 & 11,92 & 0,41 & 3,32 & 12,33 & 3,27 & 87,57 & 13,22 & 40 \\
\hline P12 & 4,21 & 1,50 & 41,17 & 0,13 & 0,21 & 2,86 & 11,65 & 0,45 & 3,31 & 12,10 & 3,73 & 86,22 & 11,20 & 50 \\
\hline P13 & 4,21 & 3,24 & 66,60 & 0,29 & 0,52 & 2,65 & 12,62 & 0,97 & 3,62 & 13,59 & 7,40 & 70,52 & 17,14 & 10 \\
\hline P14 & 4,10 & 3,06 & 59,60 & 0,20 & 0,37 & 3,09 & 14,02 & 0,72 & 3,81 & 14,74 & 5,12 & 79,68 & 15,24 & 20 \\
\hline P15 & 4,08 & 2,40 & 48,40 & 0,10 & 0,23 & 3,63 & 13,50 & 0,46 & 4,09 & 13,96 & 3,24 & 88,74 & 12,24 & 30 \\
\hline P16 & 4,15 & 2,40 & 35,40 & 0,07 & 0,14 & 3,31 & 12,30 & 0,30 & 3,61 & 12,60 & 2,36 & 91,80 & 10,24 & 40 \\
\hline P17 & 4,03 & 2,32 & 39,60 & 0,08 & 0,18 & 3,52 & 12,82 & 0,37 & 3,89 & 13,19 & 2,74 & 90,68 & 12,22 & 50 \\
\hline P18 & 3,92 & 2,46 & 36,80 & 0,10 & 0,20 & 3,33 & 13,34 & 0,39 & 3,73 & 13,73 & 2,78 & 89,58 & 19,34 & 60 \\
\hline P19 & 3,96 & 3,12 & 35,80 & 0,05 & 0,16 & 3,03 & 9,52 & 0,30 & 3,33 & 9,82 & 3,40 & 90,84 & 20,06 & 70 \\
\hline
\end{tabular}

Revista Árvore, Viçosa-MG, v.35, n.6, p.1235-1243, 2011 


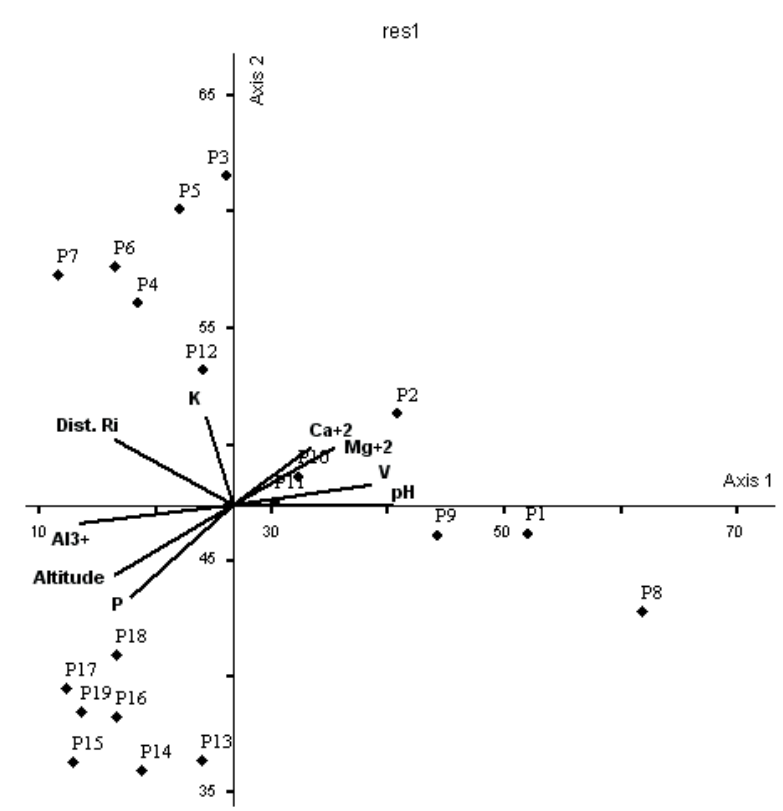

Figura 2 - Diagrama de ordenação de parcelas produzido pela análise de correspondência canônica, baseada na distribuição do número das 57 espécies arbóreas com 10 ou mais indivíduos na margem esquerda do rio Gualaxo do Norte, Mariana, MG.

Figure 2-Diagram of ordination of plots produced by the analysis of canonical correspondence, based on the distribution of the number of the 57 tree species with 10 or more individuals in the left bank of Gualaxo do Norte river, Mariana, MG.

valores de $\mathrm{pH}$ se localizavam principalmente às margens do rio, nos blocos 1 e 2, onde o relevo possuía menor declividade, podendo considerar essa área como mais favorável às plantas. Essas parcelas localizam-se em zona de depósito de nutrientes que aportavam com as cheias e com a lixiviação das encostas.

Em geral, as parcelas apresentaram baixos teores de $\mathrm{P}$, exceto as parcelas do bloco 3 , que mostraram valores mais elevados. Os valores de $\mathrm{P}$ encontrados neste trabalho são maiores dos que de Camargos (2004) e Martins et al. (2003), porém ainda são considerados baixos segundo a classificação de Tomé Júnior (1997). Os resultados para Potássio $(\mathrm{K})$ variaram entre baixo e médio. O cálcio $\left(\mathrm{Ca}^{+2}\right)$ apresentou baixos teores, com todas as amostras abaixo de $2 \mathrm{cmol} / \mathrm{dm}^{3}$. Já os resultados de $\mathrm{Mg}^{+2}$ foram variados entre as parcelas.

Os teores de $\mathrm{Al}^{+3}$ foram considerados, na maioria das parcelas e em todos os blocos, altos e com valores de saturação por alumínio (m) também elevados. Valores

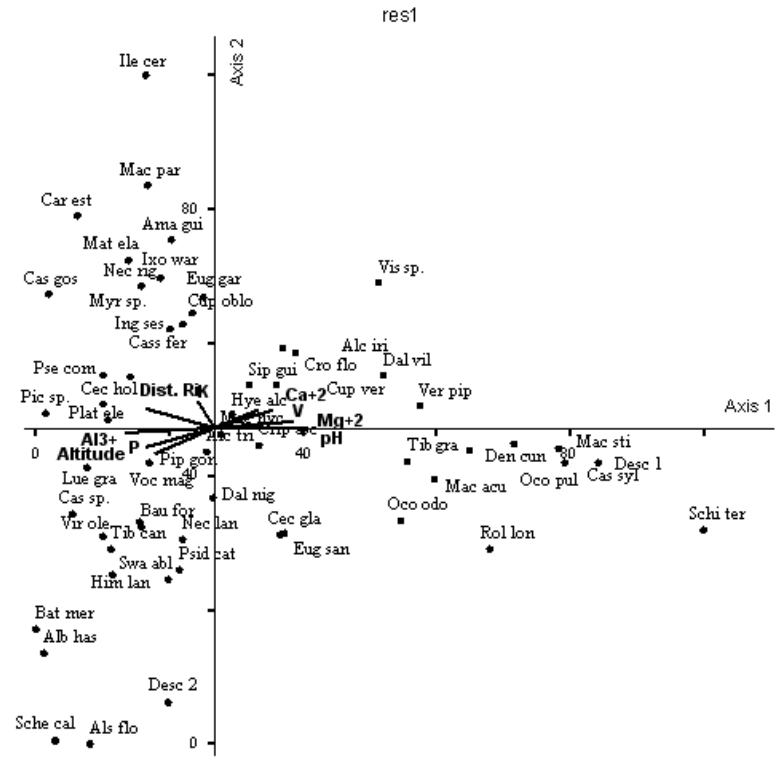

Figura 3 - Diagrama de ordenação das espécies produzido pela análise de correspondência canônica, baseada na distribuição do número das 57 espécies arbóreas com 10 ou mais indivíduos na margem esquerda do rio Gualaxo do Norte, Mariana, MG.

Figure 3-Diagram of ordination of the species produced by the analysis of canonical correspondence, based on the distribution of the number of the 57 tree species with 10 or more individuals in the left bank of Gualaxo do Norte river, Mariana, MG.

de $\mathrm{Al}^{+3}$ baixos ou nulos foram encontrados nas parcelas mais próximas ao rio, proporcionando condições mais favoráveis às plantas. Em relação aos valores de saturação por base (V) (menor que 50\%) e saturação por alumínio (m) (maior que 50\%), pode-se classificar o solo como distrófico e álico.

Os resultados seguem o padrão reconhecido nos solos da região da Zona da Mata mineira, em que nas regiões mais elevadas os solos são distróficos e com teores mais elevados de alumínio trocável, enquanto as baixadas apresentam fertilidade maior e menor acidez (MARTINS et al., 2003).

\subsection{Análise de correspondência canônica}

Os autovalores encontrados podem ser considerados baixos se comparados com os de Camargos (2004) e Martins et al. (2003), indicando a existência de gradientes curtos, ou seja, a maioria das espécies se distribui por todo o gradiente (BOTREL et al., 2002). 
Tabela 2 - Listagem das espécies arbóreas, com 10 ou mais indivíduos, nas 19 parcelas onde foram coletadas amostras de solo na margem do rio Gualaxo do Norte, Mariana, MG, com as respectivas abreviaturas e densidade total (número de indivíduos nas 19 parcelas).

Table 2 - Listing of the tree species, with 10 or more individuals, in the 19 plotswhere soil samples were collected in the bank of Gualaxo do Norte river, Mariana$M G$, with their respective abbreviations and total density (number of individuals in 19 plots).

\begin{tabular}{|c|c|c|}
\hline Nome Científico & Sigla & Densidade \\
\hline Albizia hassleri & Alb has & 32 \\
\hline Alchornea iricurana & Alc iri & 21 \\
\hline Alchornea triplinervia & Alc tri & 15 \\
\hline Alseis floribunda & Als flo & 12 \\
\hline Amaioua guianensis & Ama gui & 15 \\
\hline Bathysa meridionalis & Bat mer & 20 \\
\hline Bauhinia forficata & Bau for & 15 \\
\hline Cariniana estrelensis & Car est & 10 \\
\hline Casearia gossypiosperma & Cas gos & 51 \\
\hline Casearia sp. & Cas sp. & 74 \\
\hline Casearia sylvestris & Cas syl & 16 \\
\hline Cassia ferruginea & Cass fer & 10 \\
\hline Cecropia glaziovi & Cec gla & 24 \\
\hline Cecropia hololeuca & Cec hol & 17 \\
\hline Criptocarya aschersoniana & Crip asc & 65 \\
\hline Croton floribundus & Cro flo & 66 \\
\hline Cupania oblongifolia & Cup obl & 35 \\
\hline Cupania vernalis & Cup ver & 53 \\
\hline Dalbergia nigra & Dal nig & 43 \\
\hline Dalbergia villosa & Dal vil & 29 \\
\hline Dendropanax cuneatus & Den cun & 10 \\
\hline Desconhecida1 & Desc1 & 14 \\
\hline Desconhecida2 & Desc2 & 10 \\
\hline Eugenia gardneriana & Eug gar & 19 \\
\hline Eugenia sanderiana & Eug san & 12 \\
\hline Himatanthus lancifolius & Him lan & 22 \\
\hline Hyeronima alchorneiodes & Hye alc & 53 \\
\hline Ilex cerosifolia & Ile cer & 19 \\
\hline Inga sessilis & Ing ses & 72 \\
\hline Ixora warmingii & Ixo war & 14 \\
\hline Luehea grandiflora & Lue gra & 20 \\
\hline Machaerium aculeatum & Mac acu & 11 \\
\hline Machaerium nyctitans & Mac nyc & 37 \\
\hline Machaerium paraguariense & Mac par & 11 \\
\hline Machaerium stiptatum & Mac sti & 13 \\
\hline Matayba elaeagnoides & Mat ela & 28 \\
\hline Myrcia sp. & Myr sp. & 44 \\
\hline Nectandra lanceolata & Nec lan & 21 \\
\hline Nectandra rigida & Nec rig & 32 \\
\hline Ocotea odorifera & Oco odo & 10 \\
\hline Ocotea pulchella & Oco pul & 32 \\
\hline
\end{tabular}

Tabela 2 - Cont.

Table 2 - Cont.

\begin{tabular}{|c|c|c|}
\hline Picramnia sp. & Pic sp. & 35 \\
\hline Piptadenia gonoacantha & Pip gon & 13 \\
\hline Platypodium elegans & Plat ele & 51 \\
\hline Pseudopiptadenia contorta & Pse com & 13 \\
\hline Psidium catlleianum & Psid cat & 10 \\
\hline Rollinia longifolia & Rol lon & 11 \\
\hline Schefflera calva & Sche cal & 10 \\
\hline Schinus terebintifolius & Schi ter & 14 \\
\hline Siparuna guianensis & Sip gui & 10 \\
\hline Swartizia ablata & Swa abl & 10 \\
\hline Tibouchina candoleana & Tib can & 33 \\
\hline Tibouchina granulosa & Tib gra & 20 \\
\hline Vernonia piptocarphoides & Ver pip & 12 \\
\hline Virola oleifera & Vir ole & 18 \\
\hline Vismia sp. & Vis sp. & 13 \\
\hline Vochysia magnifica & Voc mag & 22 \\
\hline
\end{tabular}

Apesar disso, a significância das relações espécieambiente não foi prejudicada, pois a CCA produziu altas correlações nos dois primeiros eixos. Além disso, o teste de Monte Carlo indicou que as correlações entre a abundância de espécies e as variáveis edáficas foram significativas em nível de $1 \%$ de probabilidade $(P=0,01)$ para os dois primeiros eixos.

A ordenação das parcelas no primeiro eixo (Fig. 2) mostrou a ocorrência de gradiente edáfico da esquerda para a direita, envolvendo diminuição da altitude, que variou de $735 \mathrm{~m}$ na cota mais elevadas a $706 \mathrm{~m}$ na calha do rio, bem como aumento da fertilidade e redução da acidez. Portanto, as parcelas mais próximas ao rio estavam correlacionadas com solos mais férteis e com baixos teores de Al. No sentido oposto, do eixo 1, as parcelas mais distantes do rio e em cotas mais elevadas estavam correlacionadas com solos pouco férteis e com maior teor de Al.

Ao longo do gradiente geomorfológico, a fertilidade do solo normalmente aumenta do topo para a rampa baixa, sendo essas variações relacionadas com a remoção de material das partes mais altas e sua deposição relativa nas mais baixas (BOTREL et al., 2002; MARTINS et al., 2003).

A ordenação das espécies nos eixos (Figura 3) indica que as espécies Albizia hassleri, Bathysa meridionalis, Cariniana estrelensis, Casearia gossypiosperma, Casearia sp., Cecropia hololeuca, Himatanthus lancifolius, Luehea grandiflora, Picramnia sp., Platypodium elegans, Pseudopiptadenia contorta,

Revista Árvore, Viçosa-MG, v.35, n.6, p.1235-1243, 2011 
Tibouchina candoleana e Virola oleifera eram mais abundantes nas parcelas mais distantes do rio, com solos de maior acidez, baixa fertilidade e maior altitude. Esse grupo de espécies resistentes a condições edáficas mais seletivas, com elevada acidez e fertilidade muito baixa, apresenta potencial para utilização em projetos de recuperação de áreas degradadas, principalmente de encostas e topo de morros (MARTINS et al., 2003).

Na outra extremidade do gradiente, outro grupo de espécies mostrou-se correlacionado com melhores condições de fertilidade, maior proximidade do rio e menor acidez. Nesse grupo, destacam-se Casearia sylvestris, Dalbergia villosa, Dendropanax cuneatus, Machaerium aculeatum, Machaerium stiptatum, Ocotea odorifera, Ocotea pulchella, Rollinea longifolia, Schinus terebinthifolius, Tibouchina granulosa, Vernonia piptocarphoides e Vismia sp., que apresentaram os maiores valores positivos no eixo 1. Essas espécies têm sido amostradas em muitos levantamentos florísticos e fitossociológicos realizados em matas ciliares do Brasil extra-amazônico (RODRIGUES; NAVE, 2000), podendo ser recomendadas para a restauração florestal nesses ambientes.

Schinus terebinthifolius, apesar de encontrada em outras formações florestais, pode ser indicada para plantio nas margens de rios e lagos, pois suporta encharcamento temporário por até 90 dias consecutivos (LIRA et al., 2008). Casearia sylvestris é considerada generalista por hábitat (OLIVEIRA FILHO; RATTER, 2000), apresentando-se, neste estudo, como preferencial por solos com maior fertilidade, corroborando resultados encontrados por Botrel et al. (2002) e Martins et al. (2003).

Segundo Lobo e Joly (2000), o estresse imposto pela saturação hídrica do solo tem caráter fortemente seletivo. O alagamento elimina os espaços de ar do solo, limitando as trocas gasosas com a atmosfera, e em poucas horas as raízes e os microrganismos consomem o oxigênio presente na água, criando um ambiente hipóxico ou anóxico. A duração e a frequência da saturação hídrica do solo definem características abióticas particulares, que afetam significativamente os processos bióticos como a taxa de decomposição, a germinação e o recrutamento, definindo a distribuição espacial das espécies ao longo de um gradiente perpendicular a um curso d'água, bem como a estrutura da vegetação.
O conjunto de resultados indicou que as variações na fertilidade, acidez do solo e cota altimétrica ao longo do gradiente topográfico estavam influenciando na distribuição da vegetação arbórea nesse gradiente. Apesar desses resultados, Botrel et al. (2002) recomendam cautela na interpretação da distribuição de espécies, em consonância com as variáveis ambientais, pois variáveis fundamentais, como as condições de luz e os fatores de dispersão das espécies, nem sempre são facilmente perceptíveis ou mensuráveis. Além disso, algumas espécies são sensíveis às variáveis ambientais de forma interativa e não isoladamente. Assim, conclusões sobre variações das espécies em face das variáveis ambientais só devem se aproximar de alguma generalização após muitas repetições do mesmo padrão em diversas áreas.

\section{CONCLUSÕES}

O solo amostrado no trecho de Mata Ciliar do rio Gualaxo do Norte estudado pode ser enquadrado como álico e distrófico.

Albizia hassleri, Bathysa meridionalis, Cariniana estrelensis, Casearia gossypiosperma, Casearia sp., Cecropia hololeuca, Himatanthus lancifolius, Luehea grandiflora, Picramnia sp., Platypodium elegans, Pseudopiptadenia contorta, Tibouchina candoleana $e$ Virola oleifera são espécies resistentes a condições edáficas mais seletivas, com elevada acidez e fertilidade muito baixa, apresentando potencial para utilização em projetos de recuperação de áreas degradadas, principalmente de encostas e topo de morros.

Casearia sylvestris, Dalbergia villosa, Dendropanax cuneatus, Machaerium aculeatum, Machaerium stiptatum, Ocotea odorífera, Ocotea pulchella, Rollinea longifolia, Schinus terebinthifolius, Tibouchina granulosa, Vernonia piptocarphoides $e$ Vismia sp. estão correlacionadas com solos menos ácidos, mais férteis e mais próximos ao rio, apresentando potencial para a restauração florestal em áreas ciliares.

A análise de correspondência canônica evidenciou que variações na fertilidade, acidez do solo e as cotas altimétricas influenciam a distribuição da vegetação arbórea ao longo do gradiente topográfico.

\section{AGRADECIMENTOS}

Ao Programa de Pós-Graduação em Ciência Florestal da Universidade Federal de Viçosa (UFV), pelo apoio técnico; ao CNPq, pelo apoio financeiro e pela bolsa de estudo; e a todos os colegas, pelas sugestões. 


\section{REFERÊNCIAS}

BOTREL, R. T. et al. Influência do solo e topografia sobre as variações da composição florística e estrutura da comunidade arbóreaarbustiva de uma floresta estacional semidecidual em Ingaí, MG. Revista Brasileira de Botânica, v.25, n.2, p.195-213, 2002.

BRASIL. Resolução CONAMA n . 303, de 20 de Março de 2002. Dispõe sobre parâmetros, definições e limites de áreas de Preservação Permanente. Diário Oficial da União, Brasília, DF, 13 de Maio de 2002. Disponível em: <http://www.mma.gov.br/port/conama/res/res02/ res30302.htm> Acesso em: 18 out. 2008.

CAMARGOS, V. L. Florística e estrutura da vegetação arbórea e suas relações com a drenagem e os fatores edáficos num trecho de floresta estacional semidecídua no entorno da lagoa carioca - Parque Estadual do Rio Doce - MG. 2004. 51f. Tese (Mestrado em Botânica) - Universidade Federal de Viçosa, Viçosa, MG, 2004.

CRONQUIST, A. The evolution and classification of flowering plants. New York: New York Botanical Garden, 1981. 555p.

DURIGAN, G.; LEITÃO-FILHO, H. F. Florística e Fitossociologia de Matas Ciliares do Oeste Paulista. Revista Brasileira do Instituto Florestal, v.7, n.1, p.197-239, 1995.

\section{EMPRESA BRASILEIRA DE PESQUISA}

AGROPECUÁRIA - EMBRAPA. Centro Nacional de Pesquisa de Solos Manual de métodos de análise de solo. 2.ed. Rio de Janeiro: 1997. 212p.

GAUCH, H. G. J. Multivariate analysis in community ecology. Cambridge: Cambridge University Press, 1982.

\section{INSTITUTO BRASILEIRO DE GEOGRAFIA E} ESTATÍSTICA - IBGE. Disponível em:

<www.ibge.gov.br> Acesso em: 25 nov. 2008.

JACOMINE, P. K. T. Solos sob matas ciliares. In: RODRIGUES, R. R.; LEITÃO FILHO, H. F., (Eds.). Matas ciliares: conservação e recuperação. São Paulo: Universidade de São Paulo, FAPESP, 2000.

Revista Árvore, Viçosa-MG, v.35, n.6, p.1235-1243, 2011
LIRA, J. M. S. et al. Tolerância à saturação hídrica em aroeira (Shinus terebinthifolius Raddi) para fins de recuperação de mata ciliar no baixo São Francisco. In: SIMPÓSIO NACIONAL DE RECUPERAÇÃO DE ÁREAS DEGRADADAS, 7., 2008, Curitiba. Anais... Curitiba: 2008.

LOBO, P. C.; JOLY, C. A. Aspéctos ecofisiológicos da vegetação de mata ciliar do sudeste do Brasil. In: RODRIGUES, R.R.; LEITÃO FILHO, H.F., (Eds.).Matas ciliares: conservação e recuperação. São Paulo: Universidade de São Paulo, 2000.

MARANGON, L. C.; SOARES, J. J.; FELICIANO, A. L. P. Florística arbórea da Mata da Pedreira, município de Viçosa, Minas Gerais. Revista Árvore, v.27, n.2, p.207-215, 2003.

MARIANA (Cidade) Site oficial da cidade de Mariana. Disponível em

<www.mariana.mg.gov.br > Acesso em: $08 \mathrm{de}$ dez., 2008.

MARTINS, S. V. et al. Distribuição de espécies arbóreas em um gradiente topográfico de Floresta Estacional Semidecidual em Viçosa, MG. Scientia Forestalis, n.64, p.172-181, 2003.

McCUNE, B.; MEFFORD, M. J. PC-ORD.

Multivariate Analysis os Ecological Data, Version 3.0. Gleneden Beach, Oregon, USA: MjM Software Design, 1997. 43p.

MOBOT. Missouri Botanical Garden. Disponível em: <http://www.mobot.org/W3T/ search/vast.html> Acesso em: 12 dez. 2008.

MUELLER-DOMBOIS, D.; ELLENBERG, H. Aims and methods of vegetation ecology. New York: Jonh Willey \& Sons, 1974. 547p.

OLIVEIRA FILHO, A. T.; RATTER, J. A. Padrões florísticos das matas ciliares da região dos cerrados e a evolução das paisagens do Brasil Central durante o Quaternário tardio. In: RODRIGUES, R. R.; LEITÃO FILHO, H.F. (Eds.).Matas ciliares: conservação e recuperação. São Paulo: Universidade de São Paulo, FAPESP, 2000. 
OLIVEIRA-FILHO, A. T. et al. Estrutura fitossociológica e variáveis ambientais em um trecho da mata ciliar do córrego dos Vilas Boas, Reserva Biológica do Poço Bonito, Lavras (MG). Revista Brasileira de Botânica, v.17, n.1, p.67-85, 1994.

OZÓRIO, T. F. Potencial de uso da serapilheira na recuperação de áreas degradadas por mineração de ferro, Mariana - MG. 2000. 62f. (Mestrado em Ciência Florestal) - Universidade Federal de Viçosa, Viçosa, MG, 2000.

RIBAS, R. F. et al. Composição florística de dois trechos em diferentes etapas serais de uma Floresta Estacional Semidecidual em Viçosa, Minas Gerais. Revista Árvore, v.27, n.6, p.821-830, 2003

RODRIGUES, R. R.; NAVE, A. G. Heterogeneidade florística das matas ciliares. In: RODRIGUES, R. R.; LEITÃO FILHO, H. F., (Eds.). Matas

ciliares: conservação e recuperação. São Paulo: Universidade de São Paulo, FAPESP, 2000.

ROYAL BOTANICAL GARDENS. Kew Index Kewensis on compact disc - Manual. Oxford: Oxford University Press, 1993. 67p.
SILVA, A. F. Composição Florística e estrutura fotossociológica do estrato arbóreo da Reserva Florestal Professor Augusto Ruschi, São José dos campos, SP. 1989. 163f. Tese (Doutorado em Ciências - Área de Biologia vegetal) - Universidade Estadual de Campinas, Campinas, 1989.

SOUZA, L. A.; SOBREIRA, F. G.; PRADO FILHO, J. F. Cartografia e diagnóstico geoambiental aplicados ao ordenamento territorial do município de Mariana - MG. Revista Brasileira de Cartografia, v.57, n.3, p.189-204, 2005.

SOUZA, V. C.; LORENZI, H. Botânica sistemática - guia ilustrado para identificação das famílias de angiospermas da flórea brasileira baseado em APGII. Nova Odessa: Plantarum, 2005.

TER BRAAK, C. J. F.; PRENTICE, I. C. A theory of gradiente analysis. Advances in Ecological Research, v.18, n.2, p.271-317, 1988.

TOMÉ JÚNIOR, J. B. Manual para interpretação de análise de solo. Guaíba, Agropecuária, 1997. 247p. 
